International Journal of Social Science and Economic Research

ISSN: 2455-8834

Volume:05, Issue:11 "November 2020"

\title{
COVID19: A STATEWISE ANALYSIS OF HEALTHCARE EXPENDITURE IN INDIA
}

\author{
Arushi Sahay \\ Third year, Bachelor's of Science in Economics, NMIMS University, Mumbai \\ DOI: 10.46609/IJSSER.2020.v05i11.013 URL: https://doi.org/10.46609/IJSSER.2020.v05i11.013
}

\begin{abstract}
This study compares the per capita expenditure of health and family welfare across different Indian states with the total cases, mortality rates, and cumulative deaths per million data for COVID19 in the respective state. It aims to comment on the efficacy of state wise healthcare expenditure in combating the ongoing pandemic.
\end{abstract}

Keywords: COVID19, India, States, Cases, Health Expenditure

At the dawn of the new decade, when we counted down to the new year, a new disease was spreading in some districts of China. Only 13 days later, the first international case was reported, in Thailand. The first case of this bizare virus landed in the world's most populous democracy on the $30^{\text {th }}$ of January, 2020. On the night of $24^{\text {th }}$ March, when Prime Minister Narendra Modi announced a nation wide lockdown for over 1.3 billion people, the total number of confirmed cases were 536, out of which 40 had recovered and there were 10 deaths. On May $31^{\text {st }}$, when total cases grew by 10,965 in the past 24 hours, and total deaths stood at 5,408, the Ministry of Home Affairs announced the first part of a phased unlocking of the economy. During the week prior to reopening, growth in cases averaged at $4.66 \%$ whereas the fatality rate averaged at $4.32 \%$. The conundrum of whether the timing of the lockdown and reopening were appropriate has sparked debate among many experts.

In general, and rightly so, the pandemic has brought the discussion in sharp focus to the country's spending on healthcare in general and a comparison with other developed \& developing countries. It is often forgotten that in India's federal structure, health is a concurrent list subject, which implies the total expenditure on healthcare is a sum of the Union and respective State Government expenditure. In public discourse the expenditure of the Union Government is looked into, but the expenditure of State Governments is usually ignored.

Public expenditure by the State Government is a major determiner of the health infrastructure of a 
state. It is expected that the higher the per capita expenditure, sustained over time, the greater is the capability for healthcare that has been built in that state. By consequence, the lower should be the total cases and death rates, as higher per capita expenditure means the availability of better and more facilities.

A quick glance at the per capita public health care expenditure of the different states creates the impression of the highly differing levels of expenditure in these areas. The size of the state as well as the population living in that area greatly contributes to this difference. The state expenditure of Health and Family Welfare has been obtained from PRSIndia. This is the revised estimated expenditure for the financial year 2019-20. The population data has been obtained from the UIDAI projections of total population for 2020. The former data source has been divided by the latter to obtain the per capita expenditure on health. The logic for using 2020 population data with 2019- 20 expenditure is that the benefits from the investment in healthcare in the previous year has to be shared by the population in the current year. The total cases and cumulative deaths is as on $3^{\text {rd }}$ November, 2020, and the data has been collected from the MyGov website. Union Territories and some small states have not been included in this analysis due to lack of availability of data.

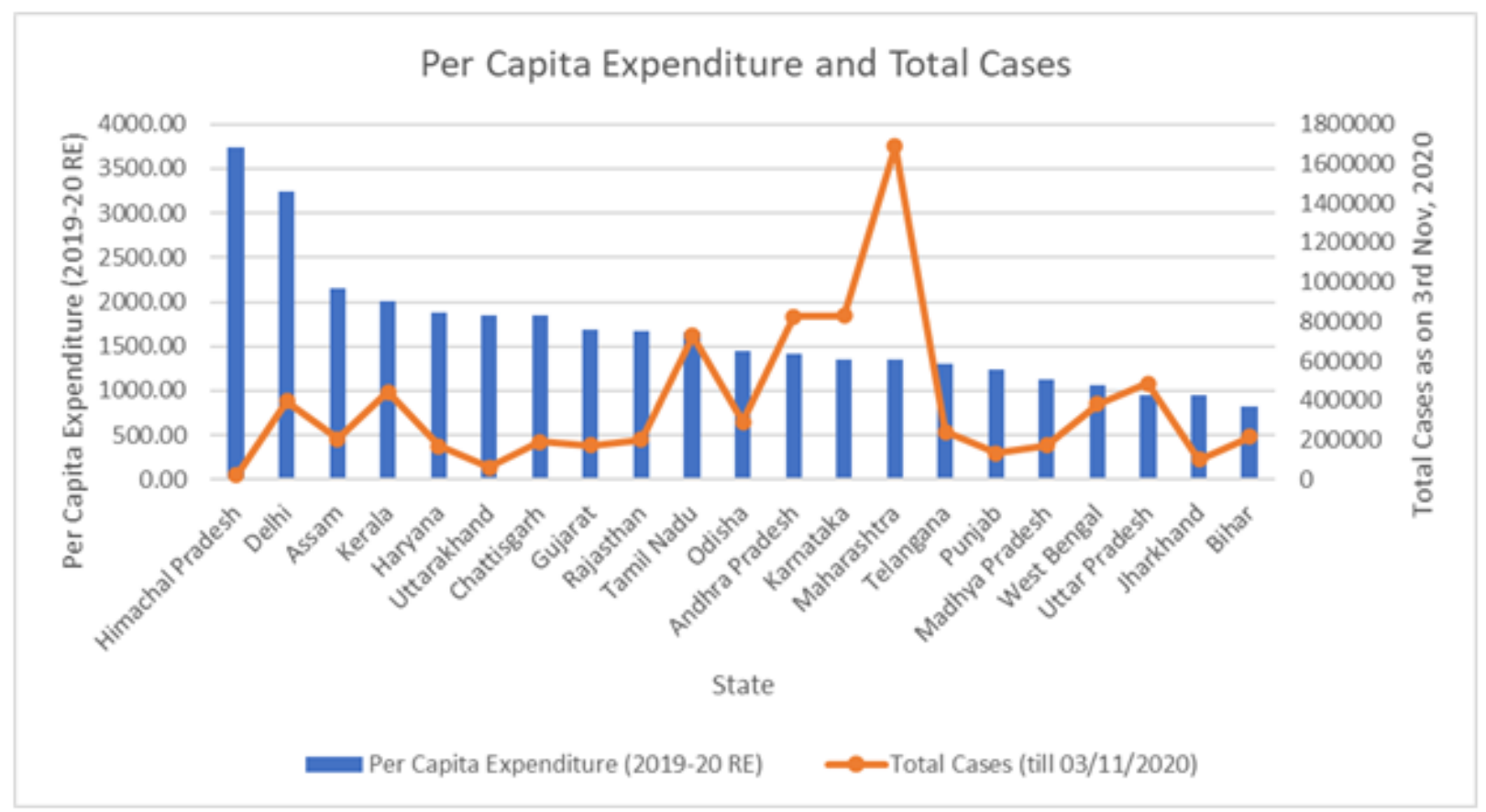

Figure 1: Per Capita Public Health Expenditure and Total Cases as on 3rd November, 2020 across States 


\section{International Journal of Social Science and Economic Research}

ISSN: $2455-8834$

Volume:05, Issue:11 "November 2020"

Figure 1 indicates that there might be some relation between the total cases in a state and the per capita healthcare expenditure. It can be seen that Maharashtra is the worst impacted state, with the highest number of total cases. The spread of the disease in Maharashtra was inevitable, as the concept of physical distancing is almost impossible in the capital of Mumbai, which is infamous for the lack of availability of space. Delhi, Kerala, and Tamil Nadu also have a high number of total cases, despite having relatively higher per capita expenditure. The state of Delhi was the primary hotspot for COVID19 cases in the month of June. One of the reasons for the high number of cases in the national capital is the laxity in wearing masks amongst the population: a large portion of the population can be seen without a mask. Additionally, the opening up of state borders also meant that patients from the neighboring rural areas in Haryana come to the national capital to seek medical aid and attention. In the case of Kerala, which was the first state to report a COVID19 positive case in India, the rise in the rate of testing as compared to the initial figures has resulted in a higher number of cases being detected.

For the eastern states of Jharkhand, Bihar, Odisha, and West Bengal there is an uncertainty of whether an adequate number of tests are being conducted. It is expected that these states should have higher number of cases, as a large number of migrants who returned to their homes belonged to these states.

However, looking at the total number of cases in a state is not a suitable indicator of a state's healthcare expenditure adequacy. The number of deaths in a state will be more apt in judging the efficacy of a state's healthcare expenditure: if the healthcare system of a state is in a good condition, there should be fewer deaths. Additionally, the total number of cases also includes the people who did not have to visit hospitals and recovered in home isolation. However, the number of people who died had to visit hospitals because of their critical condition, and hence this can be an indicator of the effectiveness of a state's healthcare expenditure.

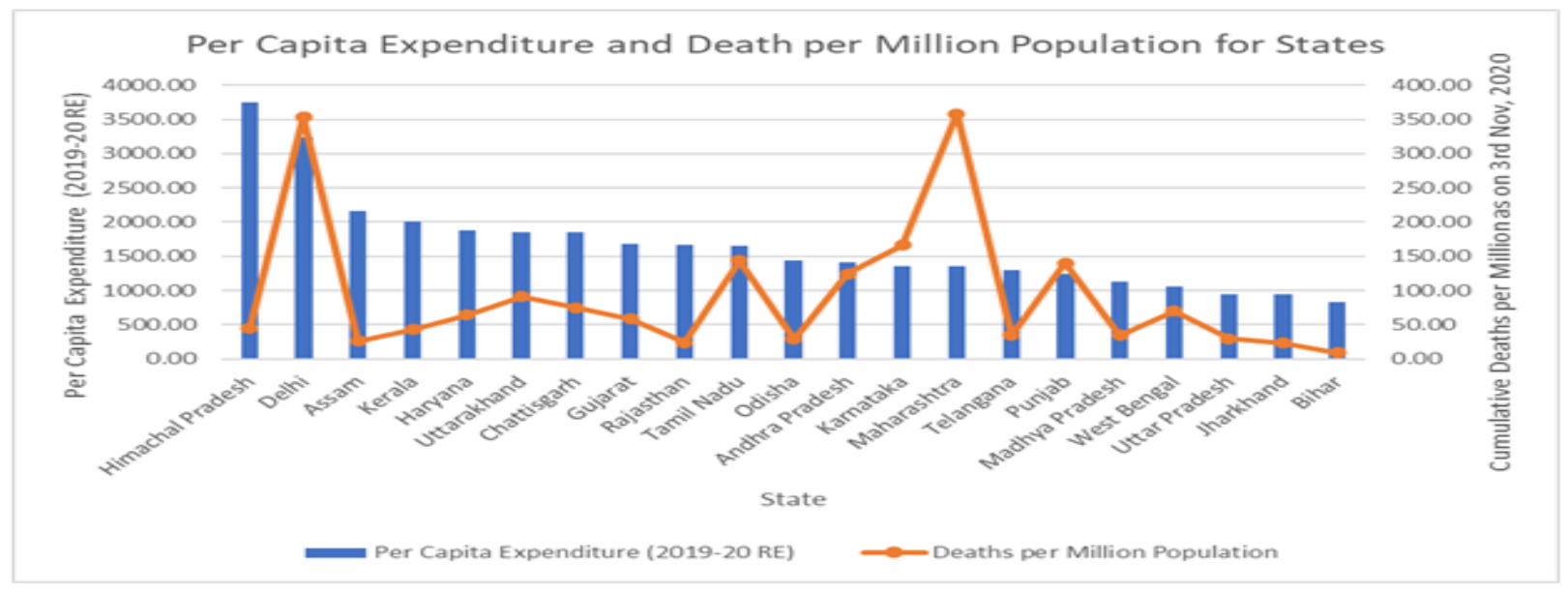




\section{International Journal of Social Science and Economic Research}

ISSN: $2455-8834$

Volume:05, Issue:11 "November 2020"

Figure 2: Per Capita Public Health Expenditure and Cumulative Deaths per 1000 population as on 3rd November, across States

Figure 2 delineates something unexpected. Delhi, a high expenditure state, has cumulative deaths per million rates similar to that in Maharashtra, which is the worst effected state. The reason for this is that the cumulative deaths are plotted as per million population in that state. Hence, this adjusts for the differences in the population of the states. Surprisingly, the state of Uttar Pradesh and Bihar have lower rates, which means that they are doing relatively well, given their population size and total number of cases.

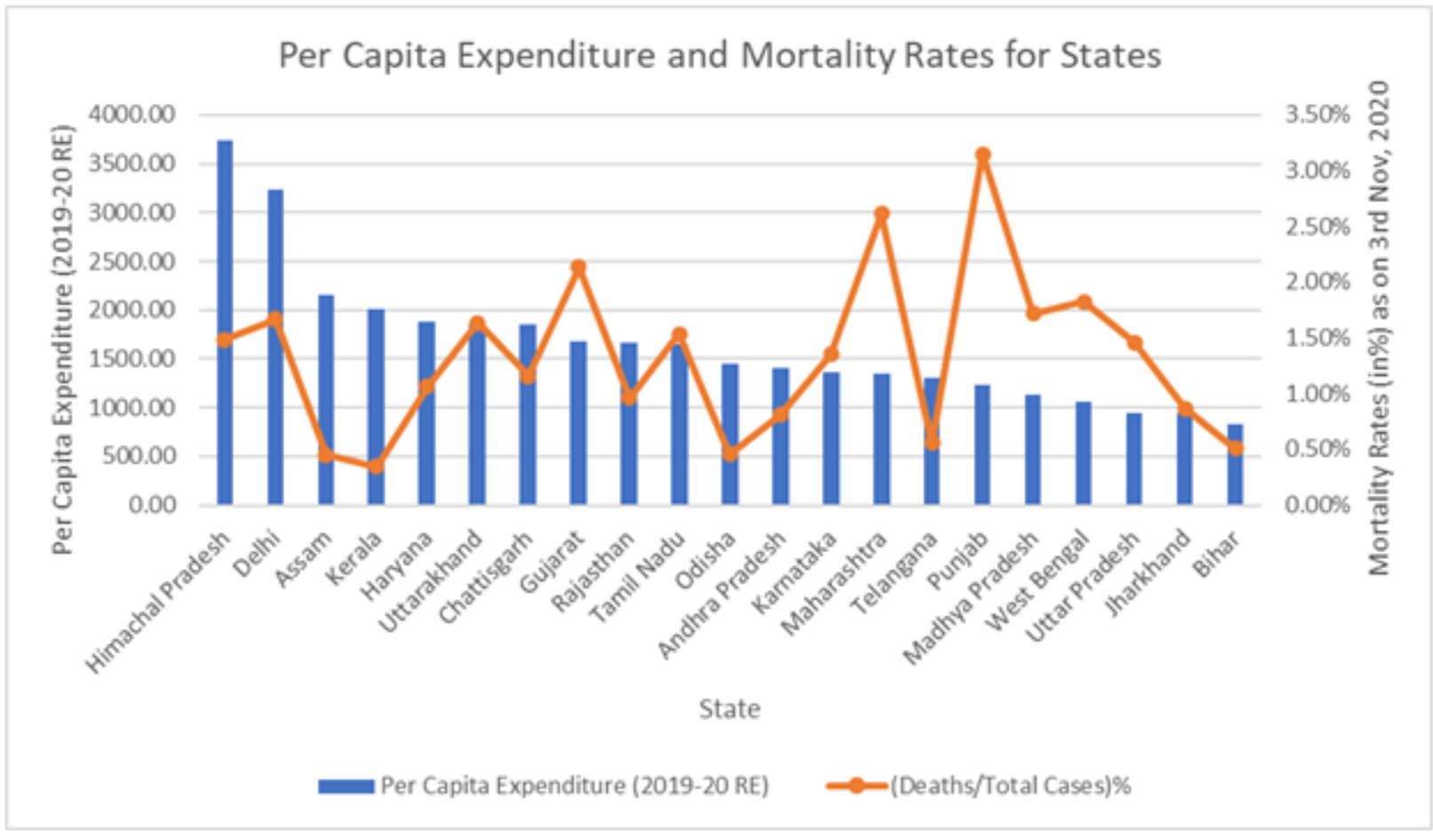

Figure 3: Per Capita Public Health Expenditure and Mortality Rates

Figure 3 shows the mortality rates, which is defined as the percentage of cumulative deaths per total cases. The results yield that Punjab has the highest mortality rate, followed by Maharashtra and Gujarat. The states with average per capita expenditure higher than the sample average per capita expenditure have a mean mortality rate which is higher than the mean mortality rates of the lower per capita expenditure states.

Therefore, although the performance of states differs based on which measure is being looked at, it appears that the states with higher per capita expenditure on health are not doing as well as they should be. Hence, the pandemic has brought to light that the healthcare expenditure by the states 
International Journal of Social Science and Economic Research

ISSN: 2455-8834

Volume:05, Issue:11 "November 2020"

has to be a greater focus over a sustained period of time for capacity building and infrastructure development in this area.

We could say that the response to the pandemic, as is reflected in the key statistics of total cases and death rates, is multi-dimensional. We have to look at interlinked factors like the social behaviours, the communication strategy of the local governments, the responses of the economic sectors, short term testing capability, and last but not the least, the cultural and festivity calendar. This is a work in progress, and with new developments and the passage of time, we will learn more about the pandemic itself, as well as the need to continually evolve multi-level response strategies.

\section{References}

Bhardwaj, A. (2020, May 20). A comparative analysis of the healthcare investments made by Indian states. Retrieved from Business Standard: https://www.business- standard.com/article/economy-policy/a-comparativeanalysis-of-the-healthcare- investments-made-by-indian-states120052001499_1.html

Bhatia, S., \& Alexander, S. (2020, March 30). Covid-19 shows why we need a healthcare reboot for India. Retrieved from Mint: https://www.livemint.com/politics/policy/will-covid-19-prompt-health-reboot11585497828527.html

Gore, S., \& Saxena, S. (2020, May 15). Health Budget vs Covid-19 Impact: How are state govts faring? Retrieved from ET Government: https://government.economictimes.indiatimes.com/news/healthcare/health-budgetvs- covid-19-impact-how-are-state-govts-faring/75744965

Rampal, N. (2020, March 25). Where do states worst hit by Covid-19 stand on health expenses? Retrieved from India Today: https://www.indiatoday.in/diu/story/wheredo-states-worst- hit-by-covid-19-stand-on-health-expenses-1659745-2020-03-25

\section{Data Sources}

Analysis of States Budget. (n.d.). Retrieved from PRSIndia: https://www.prsindia.org/parliamenttrack/budgets/state

Coronavirus (Covid19) Charts and Stats. (n.d.). Retrieved from Trading View: https://in.tradingview.com/covid19/ 
International Journal of Social Science and Economic Research

ISSN: 2455-8834

Volume:05, Issue:11 "November 2020"

COVID-19 Statewise Status. (n.d.). Retrieved from Ministry of Health and Family Welfare: https://www.mohfw.gov.in/

Statewise Aadhar Saturation. (2020). Retrieved from UIDAI: https://uidai.gov.in/images/statewise-aadhaar-saturation.pdf 